\title{
Transplante intestinal em ratos utilizando nova técnica de microanastomose sem sutura com cola e molde tubular (Cuff-Glue)*
}

\author{
Intestinal transplantation in rats using \\ the new technique of Cuff-Glue \\ sutureless microanastomosis*
}

\author{
Daniel Reis Waisberg ${ }^{1}$, Raoni de Castro Galvão², Flávio Henrique \\ Ferreira Galvão ${ }^{3}$, Luis Augusto Carneiro D'Albuquerque ${ }^{4}$
}

\begin{abstract}
Waisberg DR, Galvão RC, Galvão FHF, D’Albuquerque LAC. Transplante intestinal em ratos utilizando nova técnica de microanastomose sem sutura com cola e molde tubular (Cuff-Glue). Rev Med (São Paulo). 2009 jul.-dez.;88(3/4):207-18.

RESUMO: INTRODUÇÃO: A necessidade de sutura microvascular complexa dificulta a pesquisa do transplante intestinal no rato. A técnica de microanastomose com dispositivo tubular (cuff) é simples, porém, a persistência do dispositivo na anastomose desencadeia reação de corpo estranho e trombose. Neste trabalho descrevemos um modelo de transplante intestinal no rato com nova técnica de anastomose sem sutura com cuff e cola. MÉTODO: $\mathrm{O}$ enxerto contém o intestino delgado, colo ascendente e pedículo vascular (conduto aortomesentérico e veia porta). Na extremidade da veia e do coto intestinal, fixa-se o cuff, sobre o qual a parede é evertida. No receptor, realiza-se microanastomose aorto-aórtica manual. $\mathrm{O}$ cuffé inserido na veia mesentérica superior e fixado por ligadura circular. A margem proximal é levantada, expondo a camada íntima dos vasos, onde se deposita cola. A margem proximal é abaixada, selando a anastomose. As ligaduras fixando o cuff são retiradas possibilitando a exclusão do cuff da anastomose. Após reperfusão do enxerto, o intestino correspondente do receptor é retirado em bloco e se restabelece o trânsito intestinal utilizando a mesma técnica descrita. RESULTADOS: Observou-se adequada reperfusão do enxerto e boa patência das anastomoses. CONCLUSÃO: O modelo descrito simplifica a realização de microanastomose no transplante intestinal em ratos.
\end{abstract}

DESCRITORES: Intestino delgado/transplante; Transplante de órgãos; Microcirurgia; Anastomose cirúrgica; Ratos.

\footnotetext{
*Trabalho Vencedor do Prêmio Osvaldo Cruz, Área Cirúrgica, do XXVIII Congresso Médico Universitário (COMU) da FMUSP, São Paulo, Brasil, 2009.

1. Acadêmico do curso de medicina da Faculdade de Medicina da Universidade de São Paulo (FMUSP).

2. Acadêmico do curso de medicina da Faculdade de Ciências Médicas da Santa Casa da Misericórdia de São Paulo (FCMSCSP).

3. Médico do Serviço de Cirurgia e Transplante do Fígado do HCFMUSP.

4. Professor Titular da Disciplina de Cirurgia e Transplante do Fígado da a Faculdade de Medicina da Universidade de São Paulo (FMUSP).

Endereço para Correspondência: Secretaria da Disciplina de Cirurgia e Transplante do Fígado da FMUSP. Av. Dr. Arnaldo, 455 - 3 Andar / sala 3206. Cerqueira César - CEP: 01246903 - São Paulo, SP. e-mail: daniel_waisberg @ hotmail.com
} 


\section{INTRODUÇÃO}

$\mathrm{O}$ rato é considerado o modelo animal mais adequado para o transplante de intestino delgado (TID), visto que permite o desenvolvimento de pesquisas relacionadas à rejeição e a novos regimes de imunossupressão', à preservação de enxerto ${ }^{2,3} \mathrm{e}$ à doença do enxerto-versus-hospedeiro ${ }^{4,5}$ (GVHD, do inglês, graft-versus-host disease), entre outros. Ademais, é possível para um investigador realizar um transplante intestinal sem o auxílio de uma segunda pessoa. Entretanto, a necessidade de utilização de anastomose microcirúrgica vascular e intestinal impõe considerável complexidade ao procedimento, o que prejudica a difusão dessa prática.

A anastomose microvascular é um procedimento essencial para cirurgia reconstrutiva e para pesquisa experimental, incluindo modelos de transplante intestinal. A primeira e mais utilizada técnica foi descrita por Suarez e Jacobson ${ }^{6}$, utilizando fio e agulha. Contudo, esse método não somente traumatiza o tecido vascular como também pode ocasionar trombose e reação de corpo estranho. Acima de tudo, ele envolve dificuldades técnicas extremas, resultando em necessidade de prática extensa e cara a fim de se atingir taxas de sucesso aceitáveis ${ }^{7}$.

Para superar tais dificuldades encontradas em modelos de transplante intestinal em ratos, vários métodos alternativos têm sido introduzidos para reduzir o tempo de operação e aumentar as taxas de patência em microanastomoses vasculares, como a sleeve technique combinada à utilização de cola biológica $^{8}$ e a utilização de dispositivo denominado cuffe, ${ }^{10}$. Este é confeccionado a partir de um cateter de polietileno, de tamanho variável dependendo do tipo de anastomose, com uso de lâmina de bisturi e de microscópio microcirúrgico, conforme exposto na Figura 1. O cuff possui duas porções, cada uma de 1,5 a $2 \mathrm{~mm}$ de extensão: o corpo, a parte funcional, que é utilizada na anastomose, e a asa, usada para sua mobilização e tração. O papel de tal dispositivo já está estabelecido em diversos modelos de TID ${ }^{10-13}$. O cuffé geralmente inserido na extremidade vascular do receptor, a borda do vaso é evertida sobre o corpo e o dispositivo é fixado por ligadura circular com fio 6-0. Para confecção da anastomose, introduz-se o cuff na luz do vaso e fixa-se o dispositivo por meio de outra ligadura circular, finalizando o procedimento. Sua utilização facilita demasiadamente a realização de microanastomoses, que podem ser realizadas e aprendidas rapidamente.

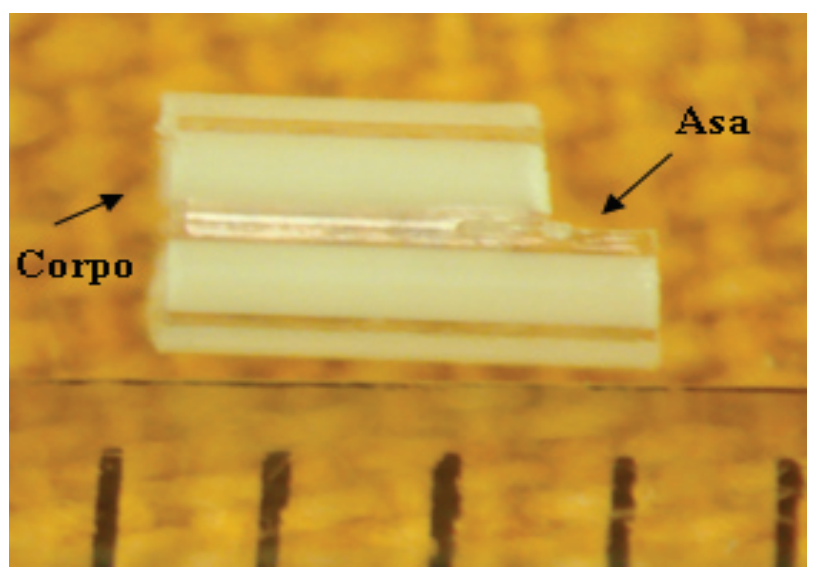

FIGURA 1. Micrografia mostrando o dispositivo de cuff, confeccionado a partir de um tubo de polietileno de 16 gauges. Seus componentes são apontados por setas. Escala em milímetros

Recentemente, Galvão et al. ${ }^{14}$ publicaram uma evolução nessa técnica, um modelo de microanastomose sem sutura utilizando cola, na qual o cuff é removido para evitar reação de corpo estranho, trombose e outras complicações de sua persistência na anastomose, como ocorre nos modelos previamente descritos ${ }^{9-13}$. Devido aos bons resultados obtidos com esse método, reportamos neste trabalho um modelo de transplante intestinal em rato utilizando tal técnica de retirada de cuff tanto para microanastomose vascular quanto intestinal.

\section{MATERIAIS E MÉTODO}

\section{Animais}

Este estudo respeitou as normas do Conselho Internacional para Pesquisa Científica com Animais de Laboratório (International Council for Laboratory Animal Science) e do Conselho de Cuidados Animais de nossa instituição. Ratos da raça Wistar foram adquiridos do nosso biotério institucional e armazenados em nosso laboratório, seguindo as orientações das organizações previamente citadas.

\section{Operação do doador}

O animal, de cerca de $250 \mathrm{~g}$, permaneceu em jejum de alimento sólido por 24 horas. Após anestesia inalatória com isoflurano e injeção intraperitoneal de cefoxitina sódica $(1 \mathrm{mg} / \mathrm{kg})$, ele foi submetido 
à laparotomia mediana ampla. Um microscópio cirúrgico foi utilizado para realizar o procedimento, com aumento variando entre 6 e 16 vezes. Após a dissecção do ligamento de Trietz, os intestinos delgado e grosso foram envolvidos em gaze umedecida com soro fisiológico e posicionados à esquerda, expondo o retroperitôneo. A aorta abdominal foi dissecada próximo à emergência da artéria mesentérica superior (AMS) e a artéria renal direita foi ligada e seccionada. A seguir, a fim de facilitar o procedimento, uma pinça de Halsted foi posicionada para tracionar o estômago e o baço para fora da cavidade abdominal, próximo à porção mais cefálica da incisão. De modo análogo, o duodeno foi tracionado para direita por outras duas pinças, expondo o mesoduodeno (Figura 2). Os vasos duodenais foram expostos e o mesocolo foi cautelosamente separado do pâncreas e epíplon. Os vasos colônicos foram preservados, mas a artéria e veia cólica média foram ligadas e seccionadas. Em seguida, os colos transverso e descendente foram separados do intestino delgado e colo ascendente. A veia mesentérica superior (VMS) foi então separada do pâncreas e tecido conectivo por cautelosa liberação e dissecção de seus vasos tributários, sendo a veia esplênica e gástrica esquerda (ramo portal) ligadas e seccionadas. A dissecção da veia porta (VP) estendeu-se até o hilo hepático. Prolongou-se a dissecção da aorta abdominal próximo à emergência da AMS, estendendo-se desde a saída do tronco celíaco e até abaixo dos vasos renais. Após heparinização sistêmica (500 UI diluídas em $3 \mathrm{~mL}$ de solução fisiológica) através de infusão na veia peniana, a aorta dissecada foi clampeada logo abaixo do diafragma e ligada abaixo da AMS com fio algodão 6-0 e seccionada abaixo do clamp e do nó, constituindo um longo conduto aortomesentérico (CAM). A VP foi seccionada próximo ao hilo hepático. O jejuno, íleo, ceco e colo ascendente em sua integridade foram removidos do animal. $\mathrm{O}$ clamp na aorta abdominal foi retirado e o animal foi sacrificado por exsanguinação.

O enxerto foi colocado em recipiente contendo $75 \mathrm{~mL}$ da mesma solução a $4^{\circ} \mathrm{C}$ (Figura 3). O conduto aorto-mesentérico e o jejuno foram canulados e o conteúdo intravascular do enxerto foi lavado por solução de Ringer lactato gelada (Figura 4). Um cateter de polietileno de $1,5 \mathrm{~mm}$ de diâmetro foi utilizado para confecção de um cuff de $4 \mathrm{~mm}$ de extensão, como previamente descrito na literatura ${ }^{10-}$ ${ }^{14}$. Para a borda jejunal e do colo ascendente, dois outros cuffs de $4 \mathrm{~mm}$ e $6 \mathrm{~mm}$ respectivamente foram feitos de modo similar, utilizando-se um cateter de polietileno de $6 \mathrm{~mm}$ e outro de $8 \mathrm{~mm}$ de extensão, respectivamente (Figura 5).

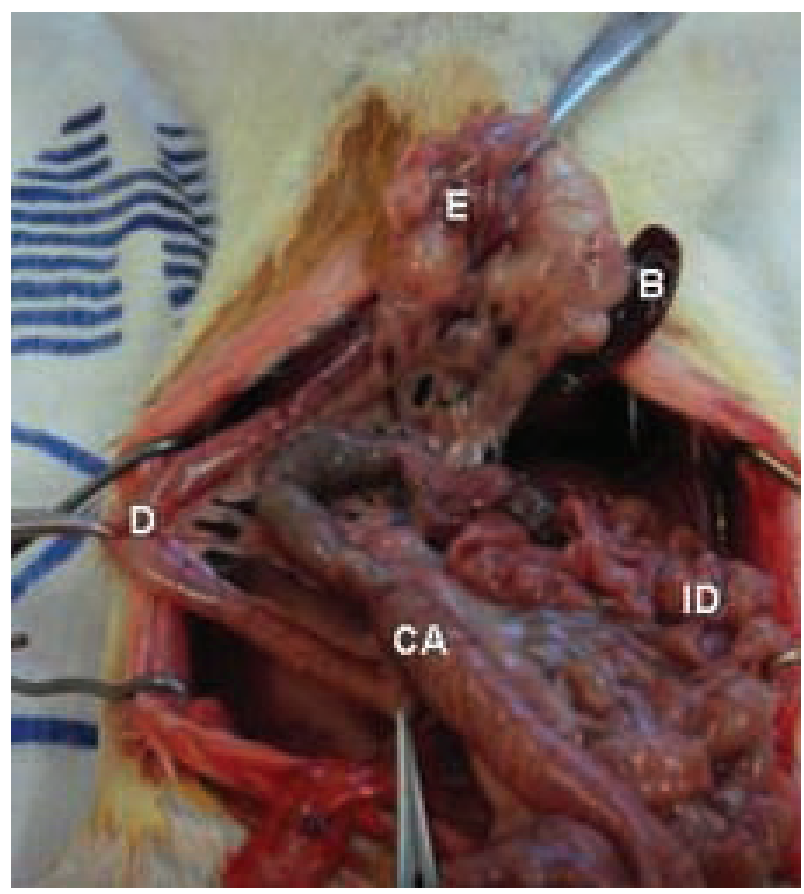

FIGURA 2. Disposição das vísceras abdominais para dissecção da veia mesentérica superior, Notar a configuração em forma de $C$ do duodeno (D) obtida pela utilização de três pinças de Halsted. O intestino delgado (ID) e colo ascendente $(C A)$, que integram o enxerto, o estômago $(E)$ e baço (B) são também apontados

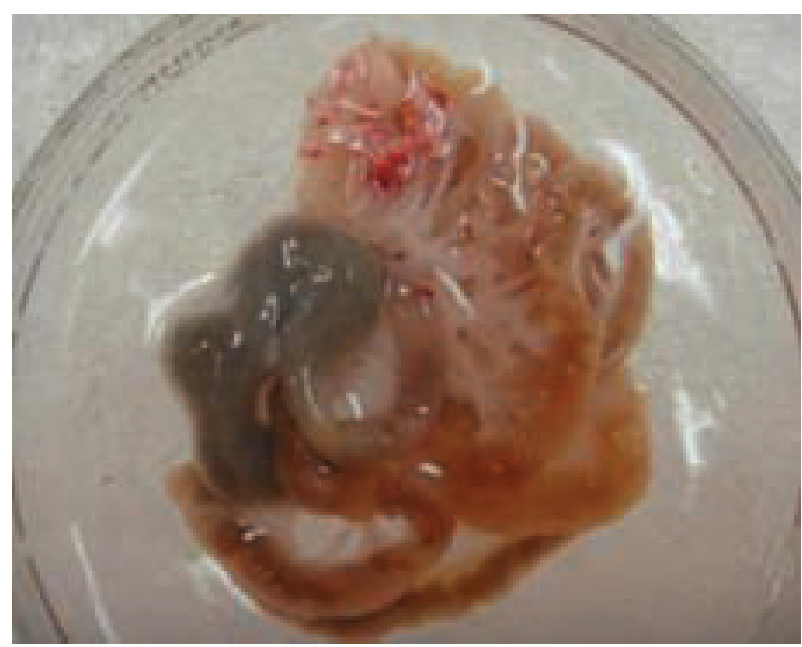

FIGURA 3. Enxerto - contendo intestino delgado, ceco e colo ascendente - retirado e colocado em recipiente com solução Ringer Lactato à $4^{\circ} \mathrm{C}$ 


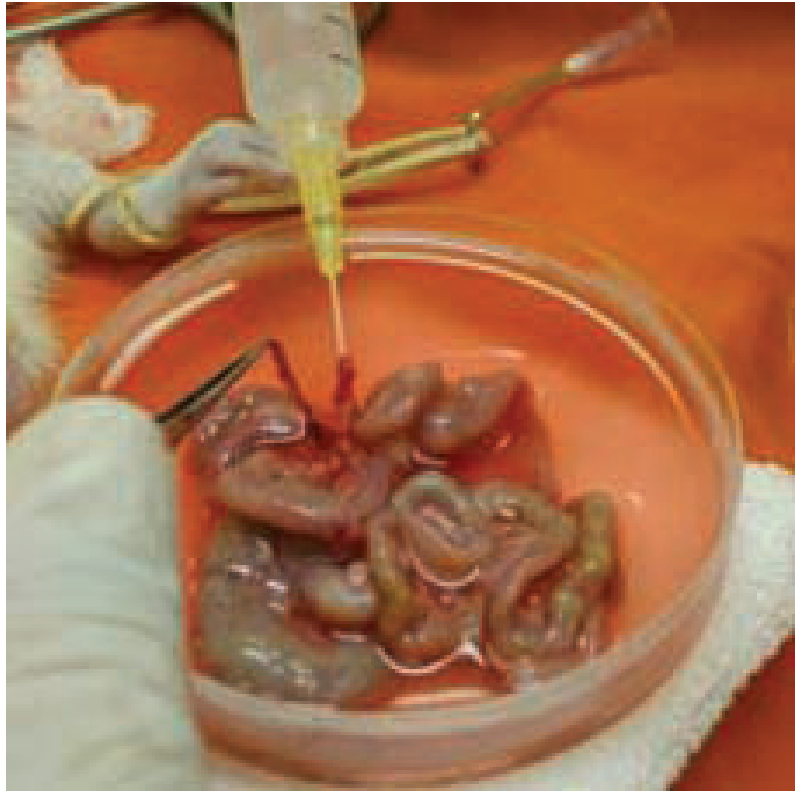

FIGURA 4. Canulação do conduto aorto-mesentérico para perfusão com solução RInger Lactato e limpeza de conteúdo intra-vascular

A extremidade portal foi introduzida no cuff apropriado e sua borda foi evertida, cobrindo a parede externa do dispositivo. Três pontos eqüidistantes (fio polipropileno 7-0) foram passados para fixar a porção distal da veia evertida na base do cuff (Figura 6). O mesmo procedimento foi realizado para a extremidade jejunal e do colo ascendente (fios polipropileno 6-0 e $5-0$, respectivamente), finalizando o procedimento de back table (Figura 7).

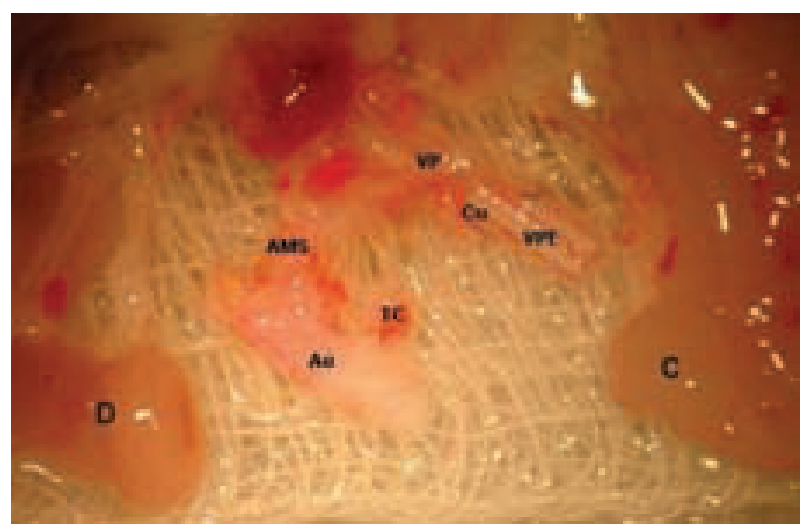

FIGURA 6. Detalhe das extremidades do enxerto, mostrando a borda jejunal (D) e do colo ascendente (C) previamente à inserção do cuff e o dispositivo $(\mathrm{Cu})$ fixado na veia porta, com parte de sua parede evertida. Ao, aorta abdominal; TC, tronco celíaco; AMS, artéria mesentérica superior; VP, veia porta; VPE, veia porta evertida

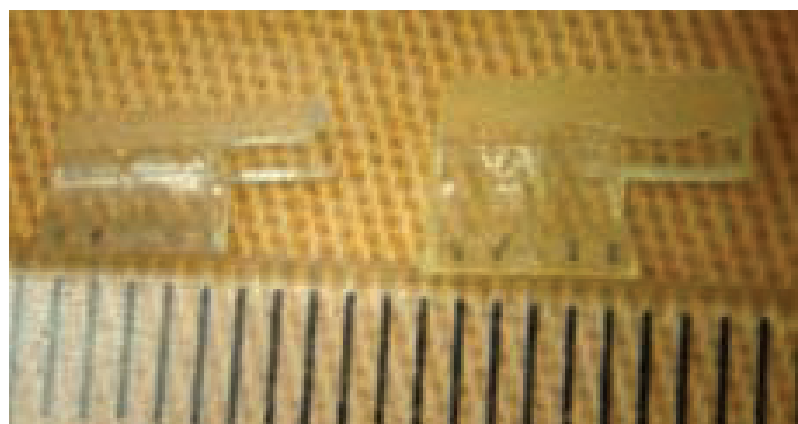

FIGURA 5. Detalhes de cuffs utilizados para anastomoses intestinais. Á direita, para intestino delgado e à esquerda, para o cólon

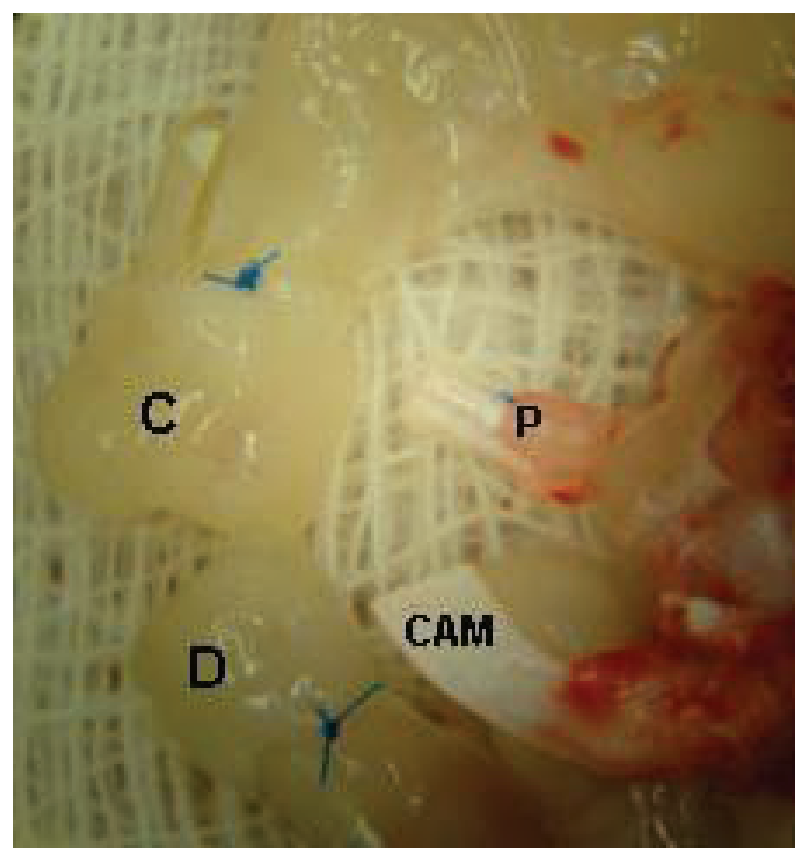

FIGURA 7. Detalhe do enxerto ao fim do processo de back table com o conduto aorto-mesentérico (CAM) e cuffs inseridos na borda jejunal (D), colônica (C) e portal (P)

\section{Operação do receptor}

Após anestesia inalatória com isoflurano e intraperitoneal com cefoxitina sódica $(1 \mathrm{mg} / \mathrm{kg})$, um animal de $270 \mathrm{~g}$ foi submetido a laparotomia mediana ampla. Ele havia sido privado de alimento sólido 24 horas antes do início do procedimento. Com auxílio de um microscópio microcirúrgico com aumento variando entre 10 e 25 vezes, após secção do ligamento de Trietz, o delicado tecido conectivo entre o duodeno e o colo ascendente e transverso foi dissecado, expondo a VMS e o os vasos colônicos direitos. A VMS também foi dissecada entre o primeiro e segundo ramos jejunais para inserção do cuff presente na veia porta do doador. Após exposição do retroperitôneo por posicionamento das vísceras em gaze úmida à direita, a aorta abdominal $(A A)$ e a 
veia cava inferior ( $\mathrm{VCl}$ ) foram dissecadas em plano infrarenal e separadas. Um segmento de cerca de $15 \mathrm{~mm}$ de AA foi clampeado proximal e distalmente, sendo uma aortomia realizada entre os clamps. O enxerto foi então colocado no abdômen esquerdo do receptor, envolvido por gaze umedecida. Um ponto simples (nylon 10-0) foi dado entre cada ângulo do CAM do doador e da aorta infra-renal do receptor. Uma sutura contínua término-lateral com o mesmo fio foi posteriormente realizada na porção medial da anastomose, partindo-se do ângulo mais distal, onde o fio não havia sido cortado (Figura 8). Um nó foi realizado ao se atingir o ângulo mais proximal, a fim de assegurar maior estabilidade à microanastomose. Em seguida, o enxerto foi colocado no abdômen direito e terminou-se a sutura na face lateral, completando a anastomose arterial. O segmento de veia mesentérica superior previamente dissecado foi isolado entre clamps e posteriormente seccionado (Figuras 9 e 10). O cuff, presente na veia porta do doador, foi introduzido na borda distal da veia do receptor e uma ligadura circular com fio 7-0 foi utilizada para fixá-lo. A porção da veia do receptor abaixo da ligadura é tracionada proximalmente, expondo a camada íntima de ambos os vasos. Palinetes de algodão são utilizados para cuidadosamente secar tais superfícies e cautelosamente derramouse cola cirúrgica (cianoacrilato) na camada íntima de ambos os vasos do doador e do receptor, ao redor de toda a anastomose. A porção de veia do receptor mencionada acima é tracionada em direção à do doador, posicionando a cola entre as bordas dos vasos e completando a anastomose. Após confirmação de aderência conveniente, as ligaduras e pontos fixando o cuff foram seccionados, desconectando-o da anastomose, o que possibilita sua retirada através da tração de sua asa (Figuras 11 e 12). Os vasos mesentéricos do receptor são ligados abaixo da anastomose porto-portal, permitindo a remoção em bloco do jejuno, íleo, ceco e colo ascendente do receptor. Os clamps são removidos da VMS do receptor e da AA. Pulsação imediata no CAM e retorno venoso por meio da VP do enxerto foram prontamente observados. A extremidade jejunal e do colo ascendente do doador foram anastomosadas em continuidade com o jejuno e colo ascendente do receptor, respectivamente, para reestabelecer o trato digestivo, utilizando-se da técnica com cuff previamente descrita para a microanastomose venosa, com exceção de que o fio de ligadura circular é 6-0 para a anastomose jejunal e 5-0 para a colônica (Figuras 13 e 14). A patência das anastomoses foi acessada pela visualização direta de circulação via microscópio, por teste de pressão e reperfusão e por secção da veia porta do receptor ou de segmento intestinal à jusante da anastomose ou por secção longitudinal desta sob auxilio do microscópio, 30 minutos após a finalização do procedimento. Posteriormente, o animal foi sacrificado por exsanguinação.

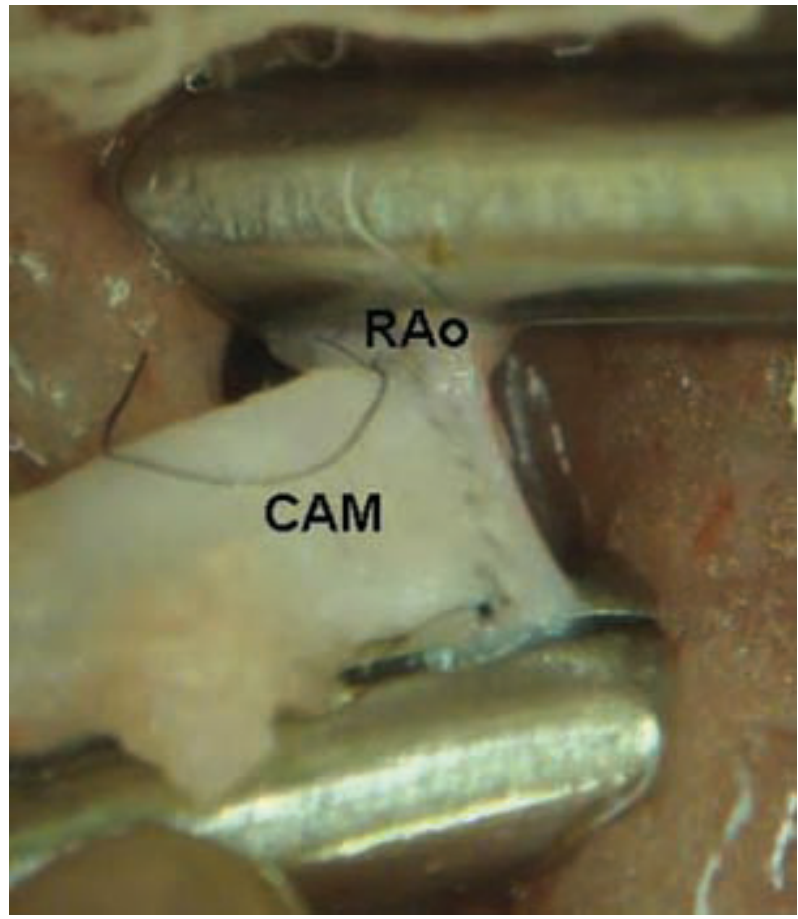

FIGURA 8. Micrografia mostrando a microanastomose vascular término-lateral entre o conduto aorto-mesentérico (CAM) do enxerto e a aorta abdominal infra-renal do receptor (RAo). Notar que a veia cava inferior do receptor não é clampeada

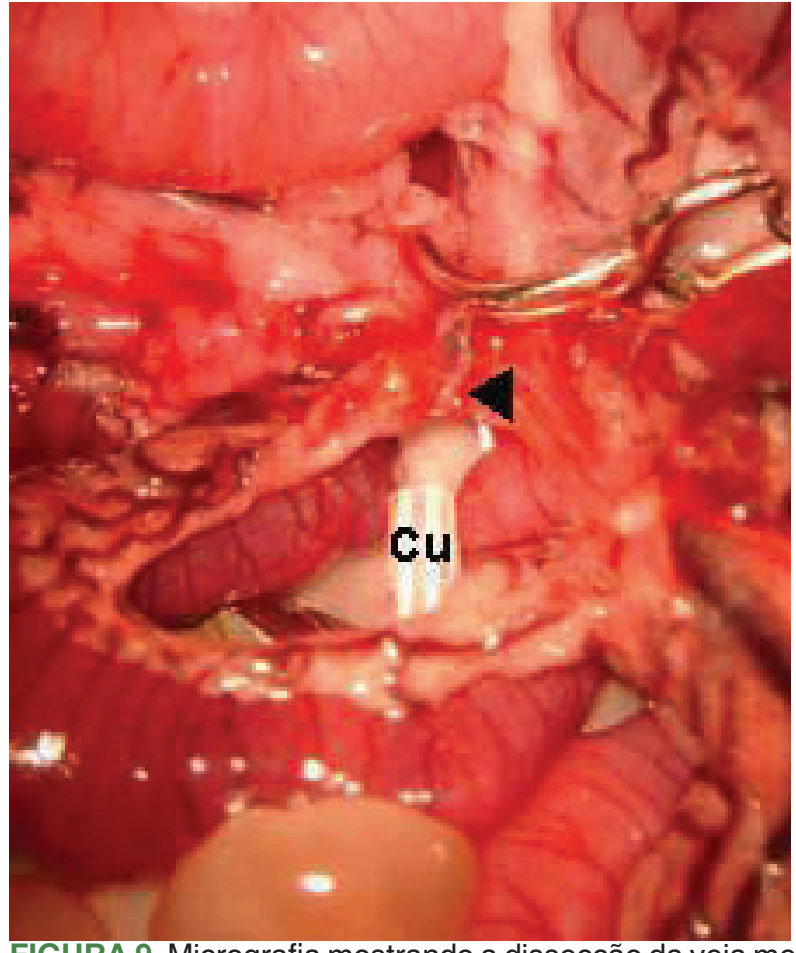

FIGURA 9. Micrografia mostrando a disseccão da veia mesentérica superior do receptor entre o $1^{\circ} \mathrm{e} 2^{\mathrm{o}}$ ramos jejunais (cabeça de seta) e sua posterior secção para inserção do cuff presente na veia porta do doador. Cu, cuff 


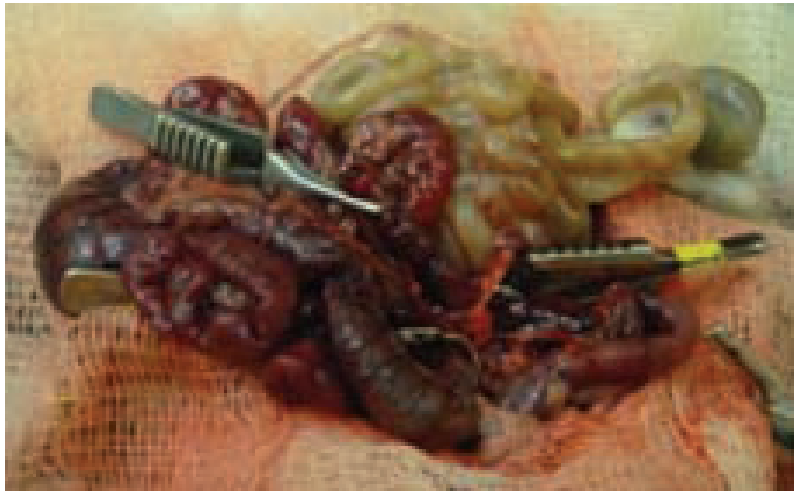

FIGURA 10. Posição do enxerto e intestino nativo no momento da anastomose venosa

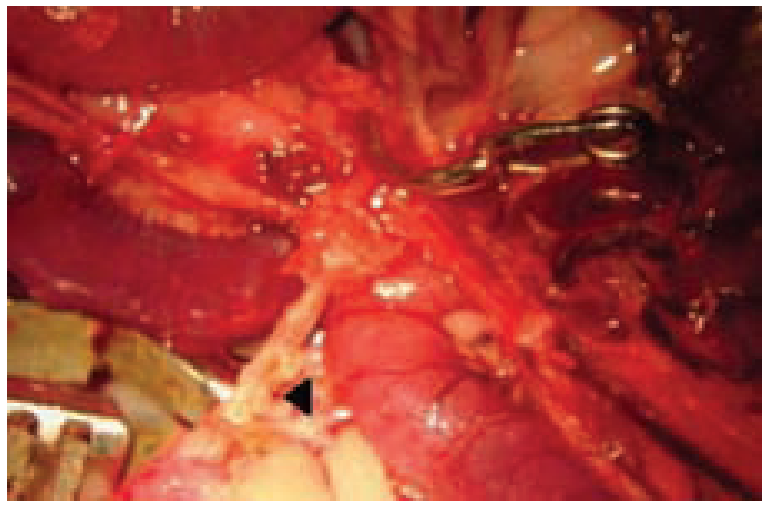

FIGURA 11. Aspecto da anastomose venosa completa, após deposição de cola e retirada do cuff (cabeça de seta). O intestino delgado original do receptor e os clamps vasculares ainda não foram removidos

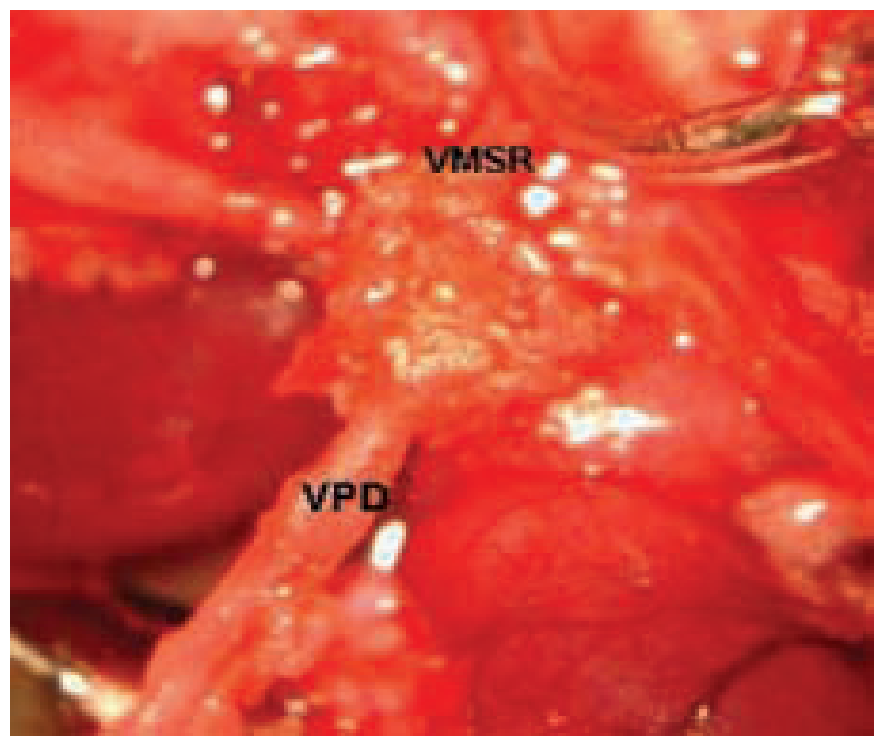

FIGURA 12. Detalhe da figura anterior, evidenciando a microanastomose venosa. VPD, veia porta do doador; VMSR, veia mesentérica superior do receptor

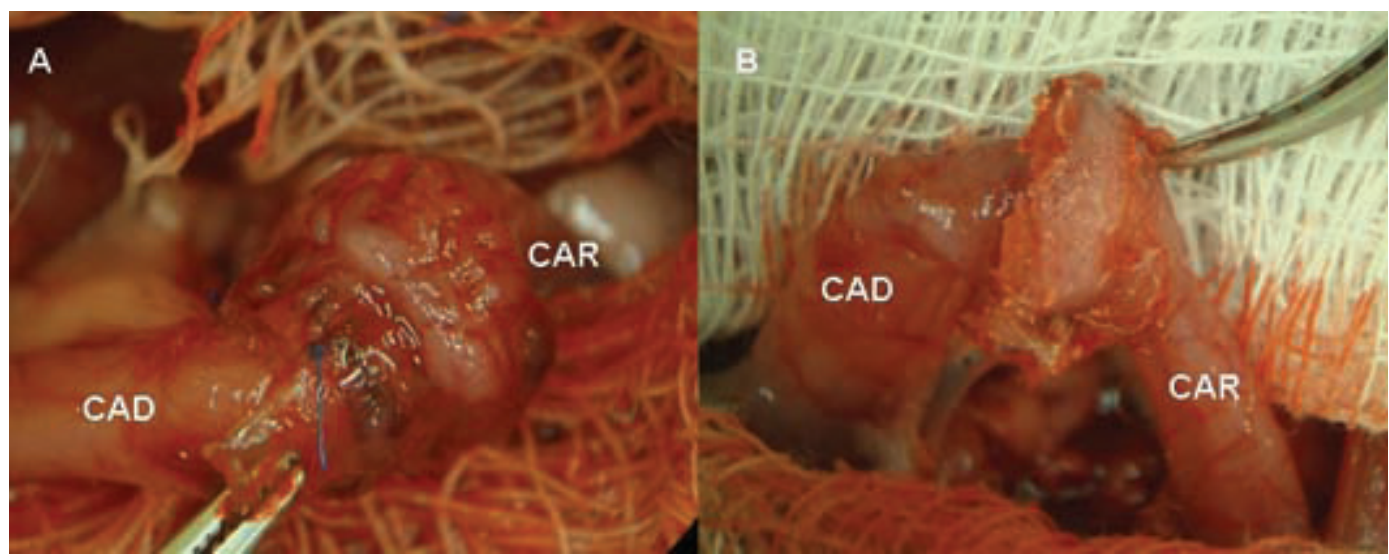

FIGURA 13. Procedimento para realização da anastomose do colo. A extremidade do enxerto contendo o cuffé aproximada da extremidade do receptor. Após inserção do cuff e sua fixação com ligadura circular 6-0, o segmento de intestino do receptor abaixo da ligadura é levantado (A). A cola é depositada na anastomose e após seu selamento, o dispositivo é retirado $(B)$. CAD, colo ascendente do doador; CAR, colo ascendente do receptor 


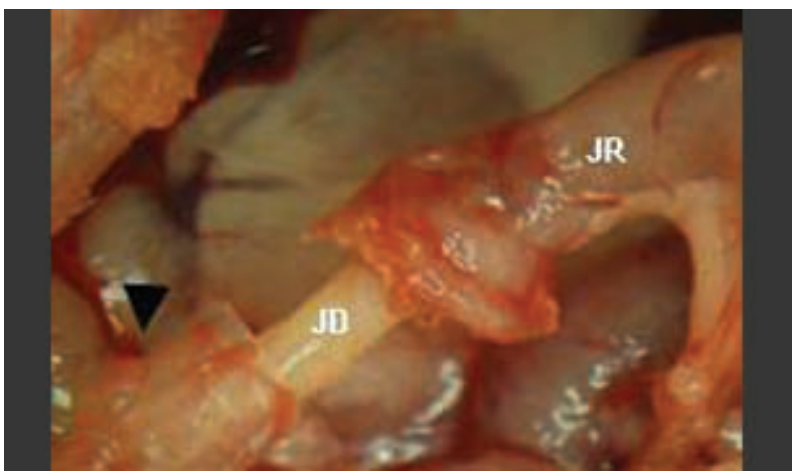

FIGURA 14. Aspecto final da anastomose entre jejuno do doador (JD) e do receptor (JR), realizada da mesma maneira que mostrado para a anastomose do colo. A cabeça de seta aponta para o cuff retirado da anastomose

\section{RESULTADOS}

Reportou-se um modelo de transplante de intestino delgado (porção jejunal e ileal), ceco e colo ascendente em rato utilizando-se microanastomoses sem sutura por meio de cuff e cola de cianolacritato. Foi observada patência total da anastomose portoportal, sem ocorrência de sangramentos, obstruções, trombose ou aneurisma. As anastomoses intestinais também estavam patentes e sem sinais de vazamento. A cola selou as bordas e localizou-se externamente à anastomose, possibilitando perfeita adesão das camadas íntimas. Tal disposição permite a retirada do cuff e garante maior probabilidade de sucesso na anastomose. Além disso, a camada dupla criada pela eversão das bordas protege a anastomose de distúrbios locais resultantes da toxicidade da cola e da ocorrência de embolia pulmonar por vazamento de cola para a circulação. O tempo para retirada dos órgãos foi de 45 minutos. Os procedimentos de back table, microanastomose arterial com sutura, microanastomose venosa com cuff e anastomoses intestinais tomaram em média 17, 32, 14 e 13 minutos respectivamente, totalizando em um tempo médio total de operação do receptor de 76 minutos. Devido à conhecida toxicidade tecidual de cianoacrilato, o animal foi sacrificado 30 minutos após a finalização do transplante.

\section{DISCUSSÃo}

Comparado a outros animais de experimentação, o rato tem sido mais freqüentemente utilizado em modelos de transplante intestinal e multivisceral. As principais vantagens consistem no custo reduzido, na fácil manipulação, na relativa resistência à sepsis, na possibilidade de realização de procedimentos por um único pesquisador e no desenvolvimento de linhagens uniformes geneticamente ${ }^{15,16}$ um fator importante para estudos imunológicos. Por outro lado, técnicas de microcirurgia são requeridas, uma vez que o rato é um animal de pequeno porte, imprimindo severa dificuldade e prática extensa aos procedimentos e reduzindo a reprodutibilidade de modelos de transplante de intestino. Desse modo, há um grande interesse no desenvolvimento de técnicas mais simples para transplante intestinal nesses animais.

O primeiro modelo de transplante intestinal em ratos utilizando metodologia microcirúrgica foi descrito por Monchik e Russel ${ }^{17}$. Um enxerto de intestino delgado, incluindo um pedículo vascular, foi implantando via microanastomose vascular términolateral manual entre o CAM do doador e a AA infrarenal do receptor e entre a VP do doador e a $\mathrm{VCI}$ infra-renal do receptor. Era necessário, portanto, o isolamento da $\mathrm{AA} \mathrm{e} \mathrm{VCl}$ do receptor por meio de duplo clampeamento. Apesar de outros modelos terem sido descritos, este permanece como o mais aceito e utilizado dentro da área de transplante intestinal experimental ${ }^{18}$.

De acordo com a posição anatômica do enxerto, o transplante de intestino delgado pode ser classificado de dois modos: heterotópico e ortotópico ${ }^{18}$. No primeiro, as duas extremidades intestinais do enxerto são exteriorizadas como estomas, sendo que o intestino delgado do receptor permanece intacto. Esse foi o modelo descrito por Monchik e Russel ${ }^{17}$ e permite análises seriadas do enxerto por meio de biópsias de mucosa seqüenciais para avaliação da rejeição. É altamente útil para estudos imunológicos, pois está relacionado a índices reduzidos de mortalidade e é relativamente fácil de ser efetuado. Entretanto, estudos fisiológicos do enxerto podem ser prejudicados por atrofia de mucosa, aumento da permeabilidade intestinal, crescimento exagerado ou translocação de bactérias potencialmente patogênicas, entre outras desvantagens advindas do isolamento do trânsito intestinal ${ }^{18}$. No modelo ortotópico, após a resecção das porções jejunal e ileal do receptor, o enxerto é anastomosado no intestino delgado remanescente. Foi primeiramente descrito por Kort et al. ${ }^{19} \mathrm{e}$ é usualmente preferido para estudos fisiológicos, imunológicos e metabólicos, visto que o enxerto é exposto ao ambiente intraluminal normal, 
o que é necessário para manutenção adequada da função ${ }^{18}$. Além disso, a rejeição do enxerto leva à morte do receptor por peritonite devido o rompimento das placas de Payer, visto que sua sobrevida depende da eficiência do órgão e ausência de infecção, proporcionando ponto final do experimento bem estabelecido.

No presente trabalho, utilizamos um modelo de transplante de intestino delgado ortotópico, em que o ceco e colo ascendente são também transplantados, previamente descrito por Galvão et al. ${ }^{20,21}$. Apesar de não houver alterações no tocante à microanastomose vascular, este modelo apresenta algumas vantagens: preservação da inervação extrínseca do enxerto, localizada ao redor da origem da artéria mesentérica superior e do tronco celíaco e possibilidade de se avaliar não somente a válvula ileocecal, o ceco e colo ascendente como a também a translocação bacteriana, pois uma parte do intestino grosso do doador é mantida.

Em qualquer modelo descrito acima, a drenagem venosa do enxerto pode ser sistêmica ou portal. A primeira é obtida conforme descrito por Monchil e Russel ${ }^{17}$. Já na segunda, a veia porta do doador é anastomosada na veia porta do receptor ${ }^{18}$. A sutura manual neste caso é de extrema dificuldade, relacionada a altas taxas de falha técnica ${ }^{18}$, de sorte que sua utilização é destinada apenas para estudos específicos ${ }^{19}$.

Reconhece-se amplamente que a técnica de sutura manual para microanastomose é um procedimento que demanda prática extensa pela dificuldade elevada ${ }^{7,8,22}$. Os resultados reportados variam razoavelmente dependendo na habilidade do cirurgião. Na maior série abordando o assunto, Zhong et al. ${ }^{23}$ reportaram um índice de sucesso de $86 \%$ e $90 \%$ em 102 e 298 ratos submetidos a TID ortotópico e heterotópico, respectivamente. Complicações na microanastomose vascular ocorreram em $1,3 \%$ do total de casos, com um tempo de isquemia quente médio (o que corresponde ao tempo para realização da anastomose) de $25 \pm 5$ minutos. Não obstante novas medidas terem sido implementadas como a minimização de trauma mecânico e isquêmico para os órgãos durante a operação do doador, marcação das extremidades da VP e CAM do doador com pequenos pontos para garantir a correta orientação do enxerto, uso de macarrão pene como prótese biológica para anastomose intestinal e administração de grandes volumes de solução cristalóide para manutenção de pressão arterial adequada durante as operações do doador e receptor. Lee et al. ${ }^{24}$, utilizando o mesmo procedimento, relataram um índice de mortalidade de $51,3 \%$ e $15 \%$ de incidência de complicações nas microanastomoses vasculares. A mais comum delas foi trombose na microanastomose porto-cava, que pode ser ocasionada por torsão devido à orientação espacial incorreta ou por falha técnica na execução da anastomose ${ }^{23}$. Convém ressaltar ainda que a microanastomose vascular deve ser completada rápido e perfeitamente, uma vez que o choque hipovolêmico após a remoção do clampeamento da $\mathrm{AA}$ e $\mathrm{VCl}$ é o fator mais crítico para determinação do pós-operatório ${ }^{23}$. Uma queda hemodinâmica é causada pelo seqüestramento de sangue em áreas localizadas distalmente aos vasos clampeados e no próprio enxerto e pela hemorragia temporária através da anastomose que ocorre independentemente da qualidade desta.

Dentro desse contexto, novas técnicas de microanastomose vascular têm sido desenvolvidas dentro dos diversos campos que envolvem microcirurgia, como a cirurgia plástica reconstrutiva, neurocirugia, otorrinolaringologia e ortopedia. Em um método chamado sleeve technique na qual introduz-se a porção proximal de um vaso dentro do lúmen de outro, sem que sutura seja feita através das paredes vasculares ${ }^{25}$. Contudo, essa técnica não pode ser aplicada em casos de anastomose entre vasos menores que $1 \mathrm{~mm}$ de diâmetro, pelo risco de obstrução vascular devido ao espaço reduzido em virtude da inserção do coto proximal ${ }^{8}$. Com a criação de cola biológica, algumas modificações foram realizadas neste modelo. Uma delas consiste em aplicar pontos simples eqüidistantes a cada $90^{\circ}$ e em depositar cola ao redor das margens da anastomose ${ }^{8}$. Outra, em introduzir o coto proximal no lúmen distal por 2 pontos internos eqüidistantes e selar o restante da anastomose com cola ${ }^{26}$. Ao permitir a localização de cola entre a anastomose, tais técnicas prejudicam a recuperação tecidual e elevam o risco de trombose local ou de embolia pulmonar, pois a cola pode migrar pela circulação. Ademais, a inserção de um coto vascular em outro determina a inconveniente disposição de camada íntima e adventícia. Uma outra linha de pesquisa para substituição da microanastomose manual envolve a utilização de diversos dispositivos mecânicos. Contudo, a manipulação complexa, a inserção de um corpo estranho rígido em uma estrutura dinâmica, a limitada disponibilidade de tais aparelhos e sua inaplicabilidade em vasos com grande discrepância 
de tamanho impedem a utilização freqüente pelos diversos centros ${ }^{8,27}$. Em vista disso, a técnica manual convencional é ainda a mais utilizada, apesar de suas complicações, que incluem: obstrução vascular por formação de hematoma resultante de sangramento entre os pontos, possibilidade de estreitamento de lúmen por pontos adicionais dados para impedir tal sangramento, reação de corpo estranho ao material de sutura e formação de trombo dentro da luz vascular pela injuria da agulha ao endotélio ${ }^{8}$. Além disso, sua complexidade determina maior tempo para sua realização. A redução no número de pontos é dessa forma necessária para minimizar o trauma cirúrgico, garantir a patência e economizar tempo. No contexto do transplante intestinal experimental, o tempo de anastomose é ainda mais crítico, visto que o animal é submetido à clampeamento sistêmico e isquemia quente. A busca por um método mais simplificado de sutura que pode ser dominado sem a necessidade de prática extensa é, pois, crucial.

Em vista dessa situação, uma técnica de anastomose sem sutura utilizando um dispositivo denominado de cuff foi descrita para TDI por Wallender et al. ${ }^{10}$. Neste modelo, tal dispositivo (preparado de um cateter de polietileno de 14 ou 16 gauges) é fixado na extremidade da veia renal esquerda do receptor por uma ligadura circular com fio 6-0, sendo a borda do vaso evertida sobre o cuff antes da fixação. Procedimento semelhante é feito com outro cuff (preparado de um cateter de mesmo material de 20 ou 22 gauges) no CAM do doador. Tais dispositivos são inseridos na VP do doador e na artéria renal esquerda do receptor e fixados por outra ligadura circular. Sendo assim, o cuff permanece na anastomose. Comparado à sutura manual, esse método pode significantemente reduzir o sangramento do local de anastomose e diminuir o tempo de isquemia quente, uma vez que é mais fácil de ser realizado. Cabe salientar que a aorta e VCI infra-renais não são clampeadas, reduzindo a morbidade do procedimento. Também é digno de nota que pode ser aprendido mais rápido. Nakao et al. ${ }^{22}$ demonstraram que pesquisadores iniciantes em TDI obtiveram um índice de sucesso de $70 \%$ com 6 semanas de treinamento em média, enquanto aqueles que praticaram o método de sutura manual levaram 8 meses em média para atingir resultados similares. De modo semelhante, o número de transplante necessário foi menor: treze no primeiro grupo comparado a trinta no segundo. O mesmo foi observado para o tempo de isquemia quente:
$10 \pm 1.4$ vs $25 \pm 5$ minutos, respectivamente. Contudo, tal modelo apresenta as seguintes desvantagens: a nefrectomia pode aumentar a morbidade da operação e alterar a resposta do receptor e, devido ao seu pequeno calibre, o fluxo proveniente da artéria renal corresponde a apenas 33\% do volume sangüíneo normal do intestino; conseqüentemente, não mais que $40 \mathrm{~cm}$ de segmento intestinal delgado (aproximadamente metade do comprimento total) pode ser transplantado ${ }^{11}$. Essas deficiências limitam a utilização desse modelo para estudos nutricionais e fisiológicos.

A fim de garantir melhor suprimento sangüíneo para o enxerto, Kawabe et al. ${ }^{11}$ modificaram o modelo de Wallender ${ }^{10}$, realizando uma microanastomose arterial aorto-aorta manual convencional, mas mantendo a anastomose venosa com cuff, com a diferença de que o dispositivo é fixado na veia porta do doador ao invés de na veia renal esquerda do receptor. Para evitar o clampeamento de grandes vasos e manter a circulação sistêmica, Nakao et al. ${ }^{12}$ aprimoraram o modelo de Kawabe ${ }^{11}$, clampeando ou a artéria renal esquerda do receptor ou parcialmente a aorta com uma pinça curva e realizando uma anastomose arterial manual envolvendo a artéria renal esquerda. Apesar do aumento na dificuldade técnica, cirurgiões iniciantes atingiram taxas de sucesso $(90 \%)$ e tempo de isquemia quente razoáveis

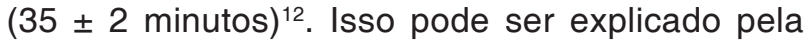
manutenção do cuff para microanastomose venosa, que é considerada tecnicamente mais desafiadora, visto que este vaso de parede fina pode ser facilmente torcido e uma tração excessiva da sutura pode resultar no estreitamento da anastomose ${ }^{11,12}$. Reporta-se que a trombose venosa no pós-operatório pode ocorrer em 19,7 a 53\% dos casos de TDI experimental ${ }^{17,28}$. No trabalho de Kawabe et al. ${ }^{11}$, se índice foi de 5\% no grupo transplantado por meio da técnica do cuff, ao passo que no grupo de sutura manual tal taxa foi de $25 \%$.

Baseado no modelo de Kawabe et al. ${ }^{11}$, Galvão et al. ${ }^{20,21}$ desenvolveram uma evolução no modelo, realizando uma microanastomose porto-portal com uso de cuff, reconstituindo assim a drenagem venosa fisiológica do enxerto. Como o ceco e o colo ascendente são também transplantados, o CAM precisa ser anastomosado término-lateralmente na aorta do receptor. Essa técnica alternativa evita isquemia visceral e instabilidade hemodinâmica, uma vez que a veia cava inferior não é clampeada. O período de treinamento também é mais breve 
( $8 \pm 3$ semanas) quando comparado ao dos modelos clássicos $(8 \pm 5.8 \text { meses })^{24}$ e o procedimento completo pode ser realizado dentro de duas horas. A microanastomose venosa pode ser feita dentro de poucos minutos, sem ocorrência de sangramento ou trombose. Ao invés da ligadura circular com fio 6-0 para fixar o cuff na borda evertida da veia, três pontos eqüidistantes 7-0 nylon são dados para estabilizar a parede venosa na base do dispositivo.

Recentemente, Zhou et al. ${ }^{13}$ descreveram o modelo intitulado 3-cuff para TID, em que as seguintes modificações foram implementadas: técnica de cuff duplo é aplicada em um longo segmento de aorta do receptor (um dispositivo para cada coto), um terceiro cuffé fixado na VP do receptor (ao invés de que no mesmo vaso do doador) e o procedimento inteiro é realizado sem uso de microscópio cirúrgico. Em sua série, a taxa de mortalidade foi de 12,5\% em virtude de complicações técnicas do método: sangramento arterial, trombose venosa e embolia aérea. Mesmo sem o uso de microscopia, o tempo da operação do doador (50 \pm 11 minutos) permaneceu dentro da média observada na literatura ${ }^{13,17,18,24}$. O uso de duas microanastomoses arteriais evita o sangramento imediato que ocorre logo após a finalização da sutura manual e remoção do clampeamento, independentemente da habilidade do cirurgião. De acordo com os autores, a inserção do cuff na VP do receptor promove menos tração, reduzindo o tempo para microanastomose venosa para 3 a 5 minutos. Xue et al. ${ }^{29}$ publicaram sua experiência com esse modelo em uma comparação retrospectiva com um grupo de ratos transplantado utilizando-se a técnica de Kawabe et al. ${ }^{11}$ (microanastomose arterial manual convencional e venosa com cuff inserido na VP do doador). Os 140 ratos transplantados pelo novo método, em relação aos 130 do outro grupo, apresentaram menor tempo cirúrgico $(81 \pm 7,4$ vs $138,7 \pm 14,3$ minutos), menor tempo de anastomose arterial (12,5 \pm 3 vs $25,2 \pm 9,3$ minutos), menor tempo de anastomose venosa $(5,6 \pm 2,2$ vs $18,1 \pm 4,5$ minutos), menor tempo de isquemia quente (31 3 vs $48,5 \pm 5,1$ minutos) e maior taxa de sobrevida $(84,6$ vs $69,3 \%)$.

Apesar dos impressionantes resultados apresentados, o trabalho é passível de críticas: os autores compararam os grupos de modo retrospectivo, incluindo casos realizados por cirurgiões iniciantes e aqueles mais experientes e o grupo da técnica de Kawabe foi transplantado primeiramente, assim a experiência cirúrgica era maior no momento de confecção do grupo do modelo de 3-cuff. Além disso, os autores reconhecem a dificuldade de se everter a borda distal do segmento de aorta e de se inserir o cuff sem auxílio de microscópio. Também já se foi estabelecido que o uso desse dispositivo diminui a luz vascular, como evidenciado no trabalho de Nakao ${ }^{12}$ previamente citado, em que a microanastomose manual entre o CAM e a artéria renal esquerda do receptor é suficiente para manter adequado suprimento sangüíneo mesentérico, o que não ocorre quando da utilização do cuff $^{\circ}$.

A persistência do cuff na anastomose desencadeia reação de corpo estranho, o que pode ocasionar trombose em longo prazo. Em um outro estudo de Nakao et al. ${ }^{30}$, foi reportada uma taxa de $40 \%$ de oclusão de anastomose venosa com uso do dispositivo de polietileno. A fim de se evitar essa complicação Galvão et al. ${ }^{14}$ descreveram uma técnica de microanastomose com cuff em que suas margens são seladas por cola (cianolacritato), permitindo a retirado do dispositivo. A cola fica localizada na parte externa da anastomose e estabelece a junção da camada íntima de ambos os vasos. É fácil de ser realizada e de baixo custo. Devido a essas vantagens, aplicamos essa técnica para o modelo de transplante de jejuno, íleo, ceco e colo ascendente, o primeiro relato na literatura de uso de cola para transplante intestinal. A forte adesão promovida pelo cianolacritato possibilita um fechamento rápido da anastomose, sem sangramento ou vazamento de conteúdo intestinal. Contudo, por ser uma cola química, promove intensa toxicidade tecidual, impedindo a manutenção da anastomose em longo prazo. O uso de três pontos eqüidistantes para fixar a borda evertida da veia na base do cuff, ao invés da tradicional ligadura com fio 6-0 é necessário para permitir a retirado do cuff do sítio de anastomose. A patência adequada observada até 1 hora no trabalho original de descrição da técnica ${ }^{14}$ e 30 minutos após a finalização do transplante neste trabalho apresenta mérito teórico, visto que utiliza a vantagem de anastomose com cuffe permite sua retirada, evitando assim os efeitos indesejáveis de sua permanência.

Em conclusão, reportou-se um modelo de transplante intestinal que utiliza uma técnica simplificada de microanastomose vascular e instestinal, a qual pode ser feita rapidamente e apresenta como vantagem a retirada do cuffempregado para facilitar o procedimento. Tal modelo é uma evolução de outros previamente descritos ${ }^{11,20,21}$, que mantém drenagem venosa portal do enxerto e adiciona a válvula íleo- 
cecal, o ceco e colo ascendente, permitindo estudos mais aprofundados da fisiologia intestinal. Devido à maior facilidade de realização, atenuando o custo de tempo e o emprego de recursos, pode contribuir para a difusão de modelos de transplante intestinal, para o ensino de microcirurgia e para o estabelecimento de uma técnica de microanastomose recentemente descrita $^{14}$.

Waisberg DR, Galvão RC, Galvão FHF, D'Albuquerque LAC. Intestinal transplantation in rats using the new technique of Cuff-Glue sutureless microanastomosis. Rev Med (São Paulo). 2009 jul.-dez.;88(3/4):207-18.

\begin{abstract}
SUMMARY: INTRODUCTION: Microsurgical difficulties hamper intestinal transplantation in the rat. Cuff anastomosis is a simple microanastomosis technique, but the tube inside anastomosis grounds foreign body reaction and thrombosis. We describe an intestinal transplantation in the rat using a new microanastomosis using adhesive called Cuff-Glue. METHOD: The graft consists of small bowel, ascending colon and a vascular pedicle containing aortomesenteric segment and portal vein. The portal margin is introduced into a cuff, everted, covering the outer wall and fixed to the base of the tube by three stitches. In the recipient, aorto-aorta hand sewn anastomosis is performed. The cuff is introduced into recipient portal vein and a ligature is performed to attach both margins to the cuff. The margin below ligature is pulled up, exposing both intimae where glue is deposited. The proximal margin is pulled down, sealing the borders by glue adhesion. Ligatures fixing the system are sectioned and the cuff is removed. After reperfusion, recipient's correspondent intestine is removed en bloc and the graft is anastomosed in continuity with the remaining intestine by Cuff-Glue anastomosis. RESULTS: It was observed adequate graft reperfusion and anastomosis patency. CONCLUSION: The described model simplifies microanastomosis performance for intestinal transplantation in rats.
\end{abstract}

KEY WORDS: Intestine, small/transplantation; Organ transplantation; Microsurgery; Anastomosis, surgical; Rats.

\title{
REFERÊNCIAS
}

1. Tanabe M, Murase M, Demetris AJ, Hoffman K, Nakamura k, Fugisaki S, et al. The influence of donor and recipient strain in isolated small bowel transplantation in rats. Transplant Proc. 1994;26:373340 .

2. Galvao FH, Waitzberg D, Logulo A, Soares S, Goncalves EL. Histological and permeability alterations in cold-stored small bowel: a comparison of University of Wisconsin and Euro-Collins solutions. Transplant Proc. 1994;26:1496.

3. Kobayashi Y, Galvao FH, Nomoto M, Murase N, Strzl $T E$, Todo $S$. The influence of graft perfusion pressure on graft viability after small bowel preservation and transplantation. Transplant Proc. 1996;28:2598-9.

4. Galvao FH, Murase N, Todo S, Zeevi A, Ye Q, Doughton CS, et al. Cytokine profile in GVHD after small bowel transplantation. Transplant Proc. 1996;28:2455.

5. Galvao FH, Ye Q, Doughton C, Murase N, Todo $S$, Zeevi A, et al. Experimental animal model of graftversus- host disease (GVHD) after small-bowel transplantation: Characteristics of the model and application to developing treatment strategies. Transplant Proc. 1997;29:700.

6. Suarez EL, Jacobson JH II. Results of small artery endarterectomy-microsurgical technique. Surg Forum. 1961;12:256-7.
7. Galvao FH, Bacchella T, Machado MC. Teaching intestinal transplantation in the rat for medical student. Microsurgery. 2007;27:277-81.

8. Seung-Kyu H, Sung-Wook K, Woo-Kyung K. Microvascular anastomosis with minimal suture and fibrin glue: experimental and clinical study. Microsurgery. 1998;18:306-11.

9. Kamada N, Calne RY. Orthotopic liver transplantation in the rat. Technique using cuff for portal vein anastomosis and biliary drainage. Transplantation. 1979;28:47-50.

10. Wallander J, Holtz A, Larsson E, Gerdin B, Lackgren G, Tufverson G. Small-bowel transplantation in the rat with a nonsuture cuff technique. Technical and immunological considerations. Transpl Int. 1988;1:135-9.

11. Kawabe T, Nakai T, Okuno K, Shindo K, Yasutomi M. Small bowel transplantation in rats using a venous cuff technique. Microsurgery. 1998;18:344-7.

12. Nakao A, Tahara K, Inoue S, Mizuta K, Takeichi T, Uchida $\mathrm{H}$, et al. Combined cuff and suture technique for orthotopic whole intestinal transplantation in rats. Microsurgery. 2002;22:85-90.

13. Zhou H, Yin L, Zhang M. Refined techniques for intestinal transplantation in rat. Transplant Proc. 2006;38:3094-6. 
14. Galvao FH, Bacchella T, Machado MC. Cuffglue sutureless microanastomosis. Microsurgery. 2007;27:271-6.

15. Hoffmann AL, Makowka L, Banner B, Cai X, Cramer DV, Pascualone A, et al. The use of FK 506 for small intestine allotransplantation. Inhibition of acute rejection and prevention of fatal graft-versus - host disease. Transplantation. 1990;49:483-90.

16. Lee S, Tung KSK, Broelsch CE, Orloff MJ. En bloc transplantation of liver, pancreas, duodenum and spleen in the rat. Transplantation. 1976;22:345-59.

17. Monchik GJ, Russell PS. Transplantation of small bowel in the rat: technical and immunological considerations. Surgery. 1971;70:693-702.

18. Timmermann W, Gassel H-J, Ulrichs K, Zhong R, Thied A. Organ transplantation in rats and mice. Microsurgical techniques and immunological principles. Deutschland: Springer; 1998. Chap. 11:83-96.

19. Kort WJ, Westbroek DL, MacDicken I, Lameijer LD. Orthotopic total small bowel transplantation in the rat. Eur Surg Res. 1973;5:81-9.

20. Galvao FH, Santos RM, Machado MA, Bacchella T, Machado MC. Simplified rat model of intestinal transplantation. Transplantation. 2005;80:1522-3.

21. Galvao FH, Santos RM, Neto AB, Machado MA, Bacchella T, Machado MC. Small bowel and colon transplantation in rats using porto-portal cuff anastomosis. Transplant Proc. 2006;38:1842-3.

22. Nakao A, Mitsuoka N, Shen SD, Tanaka N, Kobayashi
E. Rat small intestinal transplantation: a comparison of the cuff and hand-suture methods. Acta Med Okayama. 2000;54:259-64.

23. Zhong R, Grant D, Sutherland F, Wang PZ, Chen HF, Lo $S$, et al. Refined technique for intestinal transplantation in the rat. Microsurgery. 1991;12(4):268-74.

24. Lee AD, Gama-Rodrigues J, Galvao FH, Waitzberg DL. Study of morbidity in orthotopic small intestine transplantation with Wistar rats. Arq Gastroenterol. 2002;39:39-47.

25. Lauritzen C. A new and easier way to anastomose microvessels. Scand J Plast Reconstr Surg. 1978;12:291-4.

26. Hall WW, Wrye SW, Banducci DR, Ehrlich P. Microvascular anastomosis using 2-octyl cyanoacrylate in the rat femoral artery. Ann Plast Surg. 2000;44:508-11.

27. Gottlob R, Blumel G. Anastomoses of small arteries with adhesive rings. Langenbecks Arch Chir. 1966;316:962-3.

28. Sonnino RE, Harmel RP. Technical aspects of intestinal transplantation in the rat. J Invest Surg. 1988;1:55-64.

29. Xue L, Lu Y, Qiu W, Zhou H, Zhang G, Jin Z, et al. Surgical experience of refined 3-cuff technique for orthotopic small-bowel transplantation in rat: a report of 270 cases. Am J Surg. 2009;198:110-21.

30. Nakao A, Ogino Y, Tahara K, Uchida H, Kobayashi E. Orthotopic intestinal transplantation using the cuff method in rats: a histopathological evaluation of the anastomosis. Microsurgery. 2001;21:12-5. 